\title{
INTRATHORACIC ESOPHAGEAL REPLACEMENT IN THE DOG WITH THE USE OF AN ARTIFICIAL ESOPHAGUS COMPOSED OF A COLLAGEN SPONGE WITH A DOUBLE-LAYERED SILICONE TUBE
}

Yasumichi Yamamoto, MD

Tatsuo Nakamura, MD

Yasuhiko Shimizu, MD

Kazuya Matsumoto, $\mathrm{MD}^{\mathrm{a}}$

Yukinobu Takimoto, $\mathrm{MD}^{\mathrm{a}}$

Tetsuya Kiyotani, MD

Takashi Sekine, MD

Hiroki Ueda, MTech ${ }^{\mathrm{a}}$

Yu Liu, MD

Nobushige Tamura, $\mathrm{MD}^{\mathrm{b}}$
Objectives: Intrathoracic esophageal replacement with an artificial esophagus is considered difficult. We attempted to replace the intrathoracic esophagus with an artificial esophagus composed of a collagen sponge with a double-layered silicone tube and examined the state of host tissue regeneration. Methods: A $5-\mathrm{cm}$ long gap was created in the intrathoracic esophagus in 9 dogs and repaired by interposition of our prosthesis. The dogs were fed only by intravenous hyperalimentation for 28 days. The silicone tube was removed at 29 days after the operation, and oral feeding was reintroduced. Results: One dog was put to death at each of the following times: 1, 2, 3, 3, 6, 12, and 24 months after the operation. One dog is still surviving without problems after more than 26 months. One dog died of malnutrition at 10 months. In all dogs, the host regenerated tissue had replaced the resulting gap at the time of silicone tube removal. The mucosa had fully regenerated within 3 months and the glands within 12 months. The process of stenosis and shrinkage was complete within 3 months and did not advance thereafter. The lamina muscularis mucosae were observed as islets of smooth muscle within 12 months. Although the skeletal muscle regenerated close to the anastomoses, it did not extend to the middle of the regenerated esophagus even after 24 months. Conclusions: Use of a collagen sponge with a double-layered silicone tube was shown to be feasible even in the thorax and to allow the regenerated host tissue, consisting of the mucosa, glands, and lamina muscularis mucosae, to replace the esophageal gap. (J Thorac Cardiovasc Surg 1999;118:276-86)
I patients undergoing esophagectomy, the resulting gap is currently reconstructed with autologous stomach or intestine. However, this requires invasive laparotomy, and patients lose the normal functions of digestion and absorption. Furthermore, in some cases, such reconstruction cannot be done because of previous abdominal operations. A variety of artificial esophagi have been designed to overcome these problems. ${ }^{1-10}$

From the Institute for Frontier Medical Sciences, Field of Clinical Application, Department of Bioartificial Organs, Kyoto University, and the Department of Cardiovascular Surgery, Kyoto University Graduate School of Medicine and Faculty of Medicine, ${ }^{\mathrm{b}}$ Kyoto, Japan.

Funded by JSPS-RFTF96I00203.

Received for publication Oct 7, 1998; revisions requested Dec 14, 1998; revisions received April 5, 1999; accepted for publication April 5, 1999.

Address for reprints: Yasumichi Yamamoto, MD, Institute for Frontier Medical Sciences, Kyoto University, 53 Shogoin, Kawahara-cho, Sakyo-ku, Kyoto, 606-8507, Japan.

Copyright (C) 1999 by Mosby, Inc.

$0022-5223 / 99 \$ 8.00+0 \quad \mathbf{1 2 / 1 / 9 9 0 9 5}$
However, these have consisted mainly of synthetic materials and, therefore, carry a risk of serious complications, such as leakage, ${ }^{1-7}$ infection, ${ }^{3-5}$ ulceration, ${ }^{8,9}$ granulation, ${ }^{1,2,6-10}$ and migration of the prosthesis. ${ }^{2-7,10}$ Formerly, migration of the prosthesis was considered to be the major problem to be overcome. ${ }^{1,10}$ However, when we examined these results carefully, we found that the unexpected migration of the prosthesis induced neo-epithelialization at the reconstructed site, whereas such epithelialization did not occur when the prosthesis remained at the implantation site. ${ }^{1-7}$

We have therefore manufactured an artificial esophagus using atelocollagen sponge with a silicone tube stent. ${ }^{1-16}$ After new host tissue has regenerated at the reconstruction site, ${ }^{17,18}$ the inner silicone tube is designed to be dislodged to prevent any anastomotic granulation and ulceration. We have already succeeded in replacing a $5-\mathrm{cm}$ long gap of the canine cervical esophagus using our prosthesis, and complete host tissue regeneration was recognized at the defect. ${ }^{12-16}$ In the present study, we evaluated the feasibility of using 


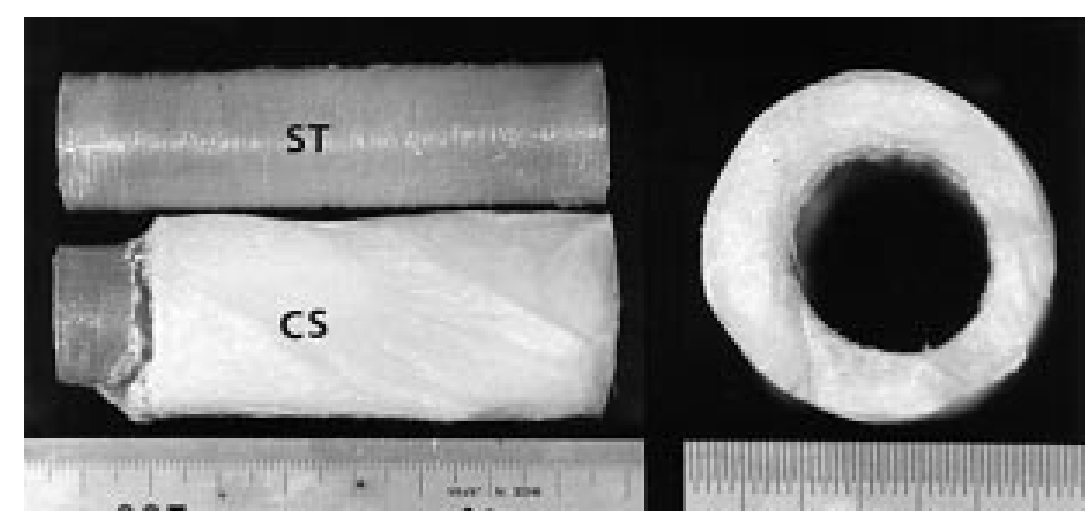

Fig 1. An overview of the artificial esophagus composed of an inner silicone tube, $18 \mathrm{~mm}$ in diameter and 0.5 $\mathrm{mm}$ thick, covered with an outer collagen sponge layer $5 \mathrm{~mm}$ thick. The material was exposed to dehydrothermal treatment. ST, Silicone tube; $C S$, collagen sponge.

this prosthesis to replace a 5-cm length of the intrathoracic esophagus. ${ }^{11}$

\section{Materials and methods}

Artificial esophagus. The artificial esophagus was a 2-layered hybrid-type prosthesis composed of an outer layer of collagen sponge and an inner silicone tube (Fig 1). The collagen used was extracted from porcine skin by enzymatic treatment and was composed of type I (70\%-80\%) and type III (20\%-30\%) atelocollagen. This atelocollagen solution was homogenized and poured into the space between the silicone tube and an outer mold. This material was frozen once at $-20^{\circ} \mathrm{C}$ and then freeze-dried for 48 hours. The dried material was subjected to dehydrothermal treatment at $10^{1} \mathrm{~Pa}$ and $105^{\circ} \mathrm{C}$ for 24 hours in a vacuum to induce cross-linkage between the collagen molecules. ${ }^{19-21}$ The prosthesis was then sterilized with ethylene oxide gas before implantation.

Operative procedures. Nine adult female beagle dogs weighing 9 to $11 \mathrm{~kg}$ were anesthetized, and a right thoracotomy was performed through the fourth intercostal space. Through an incision in the superior mediastinal pleura, a 5$\mathrm{cm}$ length of the thoracic esophagus was resected. Both ends of our artificial esophagus were inserted for about $1 \mathrm{~cm}$ into the resulting esophageal stumps; consequently the outer collagen sponge layer was attached to the native esophageal mucosa. The anastomoses were completed with 14 to 16 interrupted 3-0 Prolene sutures (Ethicon, Inc, Somerville, NJ) (Fig 2). Metal clips (PREMIUM SURGICLIP M 11.5, United States Surgical Corporation, Norwalk, Conn) were placed at the cut ends of the native esophagus as markers. After the operation, a total parenteral nutrition (TPN) tube was inserted into the inferior vena cava through the left femoral vein.

Postoperative procedures. The dogs were fed only by TPN at $330 \mathrm{~kJ} / \mathrm{kg}$ per day ( 80 calories $/ \mathrm{kg}$ per day) for 28 days after the operation without oral feeding. At 29 days, all the sutures were cut with forceps (FS-1K, Olympus, Tokyo, Japan)
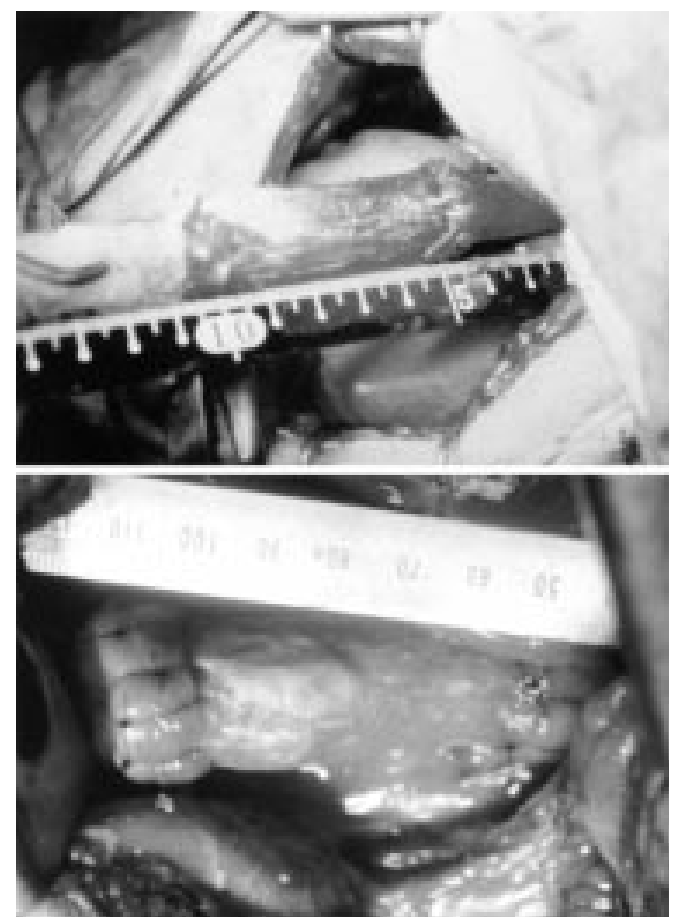

Fig 2. Operative findings. Top, The oral anastomosis is completed. Bottom, The anal anastomosis is completed. A 5-cm length of the intrathoracic esophagus was excised, and both ends of the prosthesis were inserted for about $1 \mathrm{~cm}$ into the resulting stumps.

through an endoscope (BF type 1T30, Olympus, Tokyo, Japan), and the inner silicone tube was removed through the inner lumen of the native esophagus. Oral feeding was reintroduced with a solid diet (CD-5, Clea Japan Inc, Tokyo, Japan) and a semiliquid diet (PEDIGREE, Master Foods Ltd, 
Table I. Survival time, body weight change or change rate, and stenosis and shrinkage degree in 9 experimental dogs

\begin{tabular}{|c|c|c|c|c|c|}
\hline $\begin{array}{l}\text { Dog } \\
\text { No. }\end{array}$ & $\begin{array}{l}\text { Survival time } \\
\quad(\text { mo })\end{array}$ & Cause of death & $\begin{array}{c}B W \text { change } \\
\text { (rate of change) }\end{array}$ & $\begin{array}{c}\text { Degree of stenosis } \\
(\%)\end{array}$ & $\begin{array}{c}\text { Degree of shrinkage } \\
(\%)\end{array}$ \\
\hline 1 & 1 & Planned death & $0 \mathrm{~kg}(0 \%)$ & 13 & 34 \\
\hline 2 & 2 & Planned death & $-1.0 \mathrm{~kg}(-13 \%)$ & 54 & 52 \\
\hline 3 & 3 & Planned death & $-2.0 \mathrm{~kg}(-25 \%)$ & 22 & 20 \\
\hline 4 & 3 & Planned death & $-3.5 \mathrm{~kg}(-41 \%)$ & 27 & 54 \\
\hline 5 & 6 & Planned death & $-1.0 \mathrm{~kg}(-13 \%)$ & 40 & 75 \\
\hline 6 & 10 & Malnutrition & $-2.0 \mathrm{~kg}(-25 \%)$ & 47 & 41 \\
\hline 7 & 12 & Planned death & $+2.8 \mathrm{~kg}(+35 \%)$ & 50 & 50 \\
\hline 8 & 24 & Planned death & $+1.2 \mathrm{~kg}(+17 \%)$ & 17 & 50 \\
\hline 9 & 26 & Alive & $+2.5 \mathrm{~kg}(+33 \%)$ & ND & ND \\
\hline
\end{tabular}

Although $\operatorname{dog} 7$ had $50 \%$ stenosis in the middle of the regenerated esophagus, it showed a body weight $(B W)$ gain of $35 \%$. ND, Not done.

mixed with LOVELY, Nisshin Flour Milling Co, Ltd, Tokyo, Japan). The TPN tube was also removed at this point.

One dog was put to death at each of the following times: 1 , $2,3,3,6,12$, and 24 months after the implantation operation. Esophagography was performed at the time of planned death or at $3,6,12$, and 24 months after the implantation in each of 7 dogs that survived more than 3 months (dogs 3-9 in Table I). The contrast medium was injected through the endoesophageal tube with the dog under general anesthesia. Endoscopic examination was performed in all dogs once every 3 months after the implantation and when the animal was put to death.

Calculation. The body weight change of a dog was calculated as:

$\mathrm{BW}$ change $=\mathrm{BW}$ at death $(\mathrm{kg})-\mathrm{BW}$ at removal of the stent $(\mathrm{kg})$

and the body weight change rate of a dog was calculated as:

$\mathrm{BW}$ change rate $=\mathrm{BW}$ change $(\mathrm{kg}) / \mathrm{BW}$ at removal of the stent $(\mathrm{kg}) \times 100(\%)$

where BW is body weight.

At autopsy, the regenerated esophagus including the normal parts of the native esophagus was removed and opened with a longitudinal incision. The degrees of stenosis and shrinkage were determined according to the formulas:

Shrinkage degree $=\left(1-\left[\mathrm{D}_{\min }(\mathrm{cm}) / \mathrm{D}_{0}(\mathrm{~cm})\right]\right) \times 100(\%)$

where $\mathrm{D}_{\min }$ is the minimum distance between the 2 anastomoses and $\mathrm{D}_{0}$ is the initial distance, namely $5 \mathrm{~cm}$.

Stenosis degree $=\left(1-\left[\mathrm{W}_{\min }(\mathrm{cm}) / \mathrm{W}_{\text {norm }}(\mathrm{cm})\right]\right) \times 100(\%)$, where $\mathrm{W}_{\min }$ is the minimum width of the regenerated esophagus and $\mathrm{W}_{\text {norm }}$ is the width of the normal esophagus on the anal side.

Light microscopic examination. The resected specimens were fixed with $10 \%$ formaldehyde solution, and histologic examination was performed by light microscopy with Masson's trichrome stain. The presence of smooth muscle cells was checked by immunofluorescence staining (labeled streptavidin-biotin method) using monoclonal mouse antihuman alpha-smooth muscle actin antibody (lot 035, DAKO A/S, Glostrup, Denmark). The normal canine esophageal lamina muscularis mucosae (smooth muscle) as a positive control were stained strongly positive by this alpha-smooth muscle actin antibody.

Examination with a transmission electron microscope (TEM). The deparaffinized explants were fixed with $2 \%$ osmium tetroxide, dehydrated, and then embedded in Epon resin. Ultrathin sections (70-80 nm thick) were prepared and double stained with uranyl acetate for 15 minutes and lead acetate for 5 minutes (Watson and Reynolds method) before observation with a TEM (H-7000, Hitachi Ltd., Tokyo, Japan).

This experiment was carried out in accordance with the "Guide for the Care and Use of Laboratory Animals" prepared by the Institute of Laboratory Animal Resources and published by the National Institutes of Health (NIH Publication No. 86-23, revised 1985).

\section{Results}

The inner silicone tube did not adhere to the regenerated tissue and was easily removed endoscopically by cutting all the sutures. All dogs were able to take food by mouth immediately after removal of the silicone tube. From weeks 2 to 8 after reintroduction of oral feeding, similar rumination-like behavior, involving vomiting and re-ingestion of the vomitus, was observed in all experimental dogs. However, the frequency of such refeeding behavior decreased gradually, until finally the dogs were able to take the diet without vomiting. The postoperative results and the body weight changes for the 9 dogs are shown in Table I. Seven dogs survived without problems until they were put to death. One has now survived uneventfully for more than 26 months after the operation. One dog died 10 months after the operation. Autopsy of this dog revealed stenosis in the middle of the regenerated esophagus, which had caused dry food to clog. The body weight change suggested that the cause of death in this dog was malnutrition caused by esophageal stenosis. The body weight changes ranged from $-3.5 \mathrm{~kg}$ to $+2.8 \mathrm{~kg}$ in the experimental dogs. 

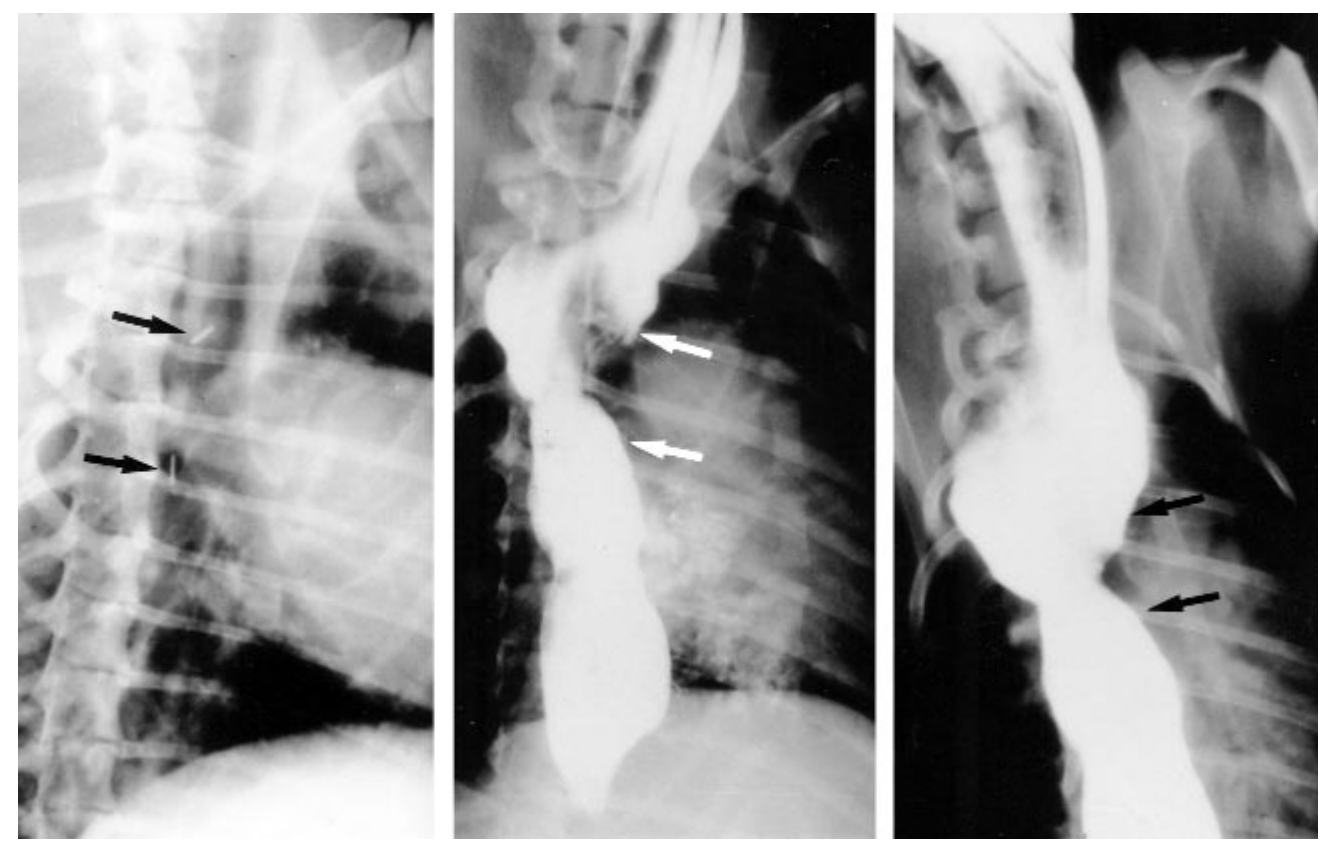

Fig 3. Esophagogram taken 3 months after the operation in dog 8. Left, Plain right anterior oblique view. Center, Right anterior oblique view. Right, Anteroposterior view. The contrast medium passed through the regenerated esophagus smoothly. Stenosis in the middle portion of the regenerated esophagus and prestenotic dilatation were evident. The anastomoses were confirmed by the metal markers in the plain right anterior oblique view. Arrows, Anastomosis.
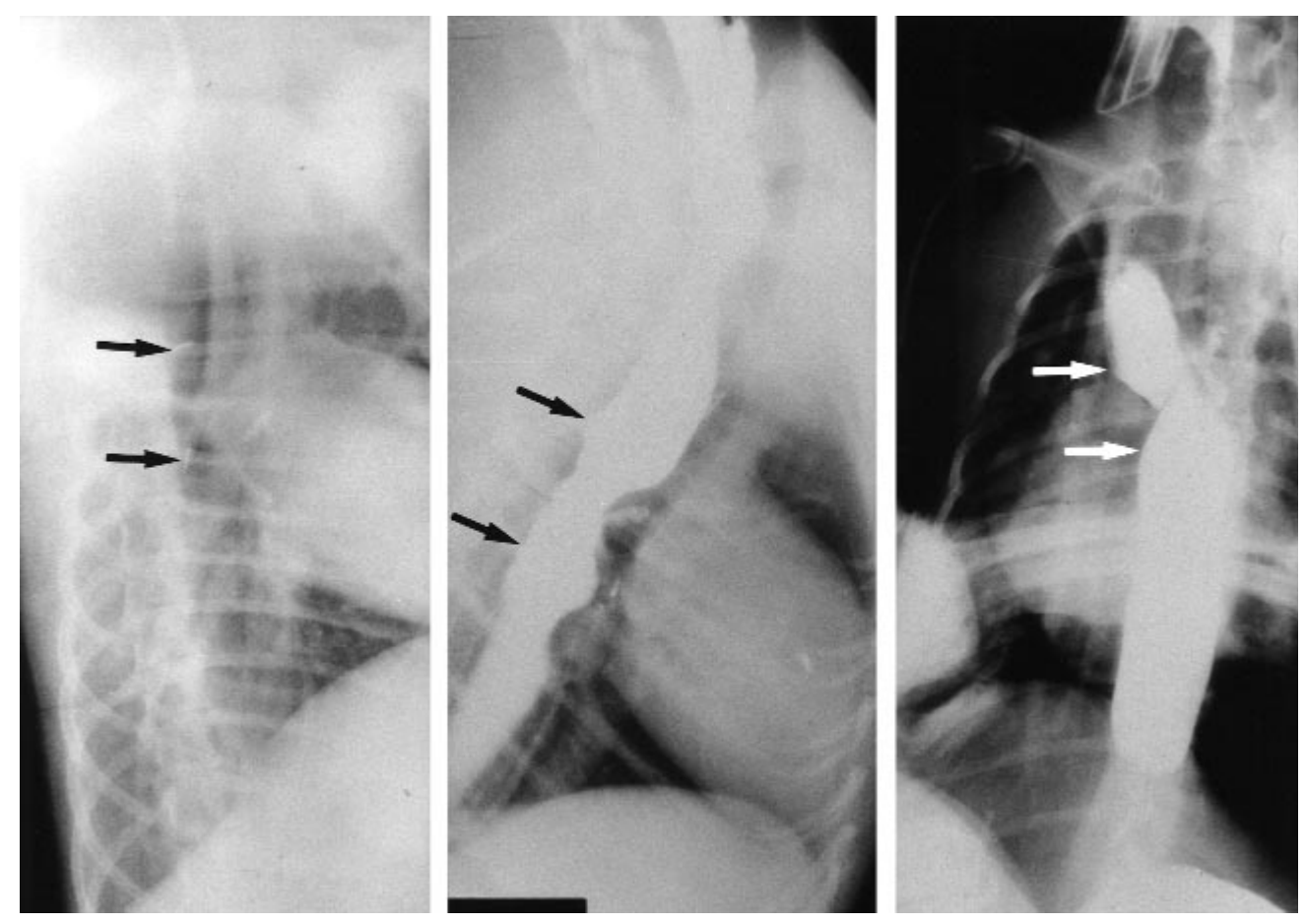

Fig 4. Esophagogram at 24 months in dog 8. Left, Plain right anterior oblique view. Center, Right anterior oblique view. Right, Anteroposterior view. Stenosis in the middle portion of the regenerated esophagus and prestenotic dilatation are still evident. Metal markers were about $3.5 \mathrm{~cm}$ of the distance, which indicated the distance of the anastomosis, and they had not changed compared with the distance at 3 months. Arrows, Anastomosis. 


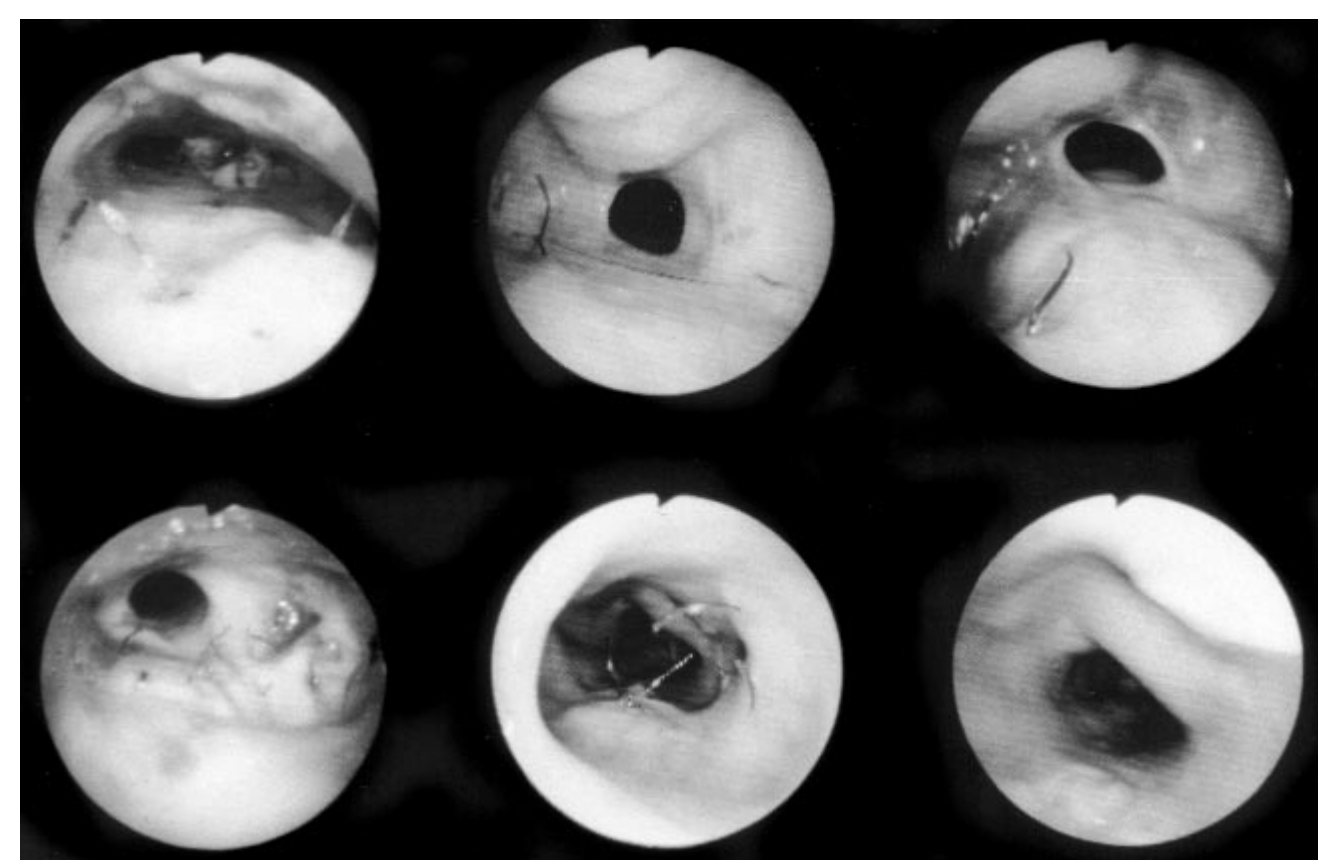

Fig 5. Endoscopic findings in dog 8. Left, 1 month; middle, 3 months; right, 12 months. Upper half, Oral side; lower half, anal side. At 1 month, the internal surface was covered by granulation tissue, although stenosis was not observed. Stenosis was evident in the middle of the regenerated esophagus at 3 and 12 months. The anastomoses were confirmed by residual sutures. The degree of stenosis at 3 months was similar to that at 12 months. The stenosis did not worsen after 3 months.

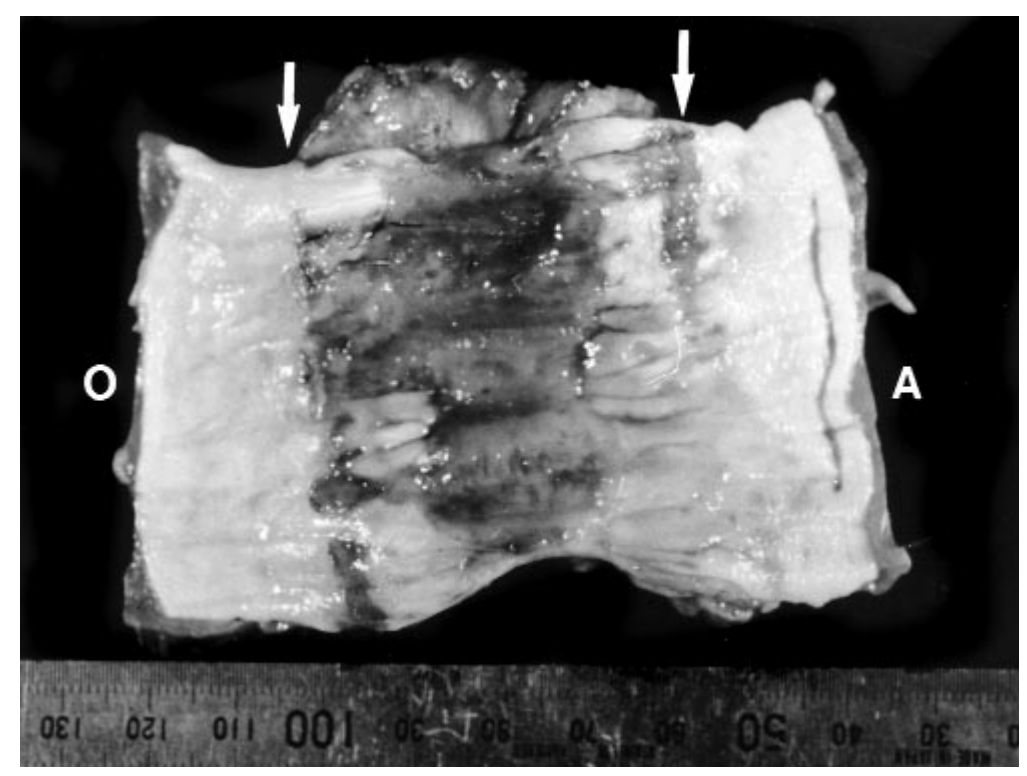

Fig 6. Macroscopic appearance of the internal surface of the regenerated esophagus at 1 month. The surface is covered with granulation tissue, and stenosis is hardly evident (stenosis degree $=13 \%$, shrinkage degree $=34 \%$ ). Arrow, Anastomosis; $A$, anal side; $O$, oral side.

Typical findings of esophagography in dog 8. Esophagography at $3,6,12$, or 24 months in 7 dogs indicated that the contrast medium passed through the regenerated esophagus smoothly, with no pooling of the medium. However, in $\operatorname{dog} 8$, mild stenosis (about $30 \%$ compared with the normal portion on the anal 


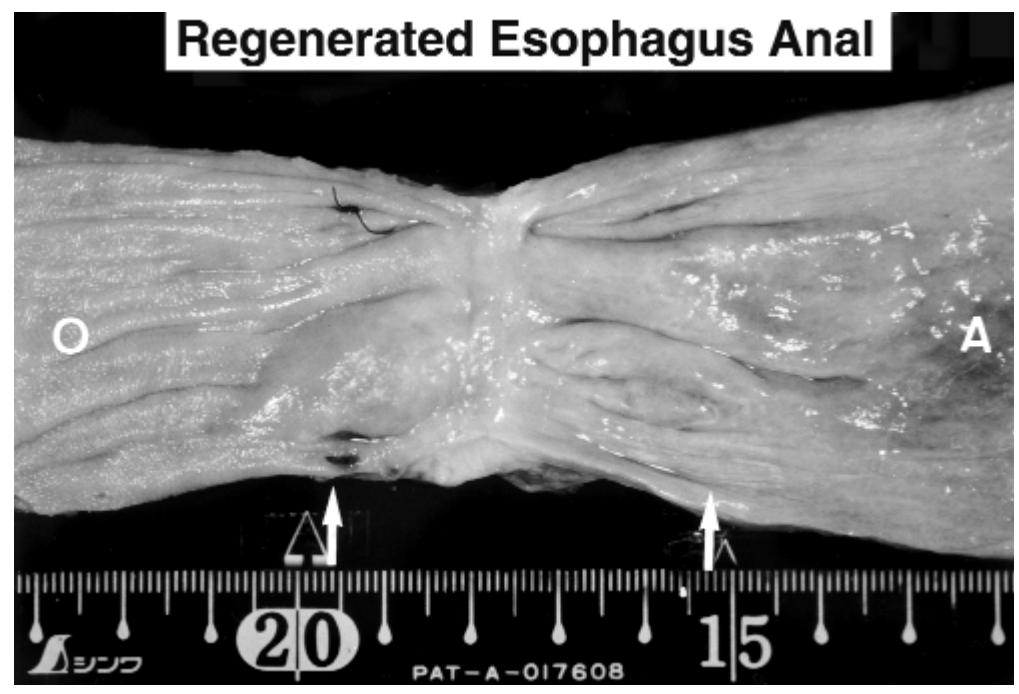

Fig 7. Macroscopic appearance of the internal surface of the regenerated esophagus at 10 months. The surface is completely covered by mucosa. Stenosis and shrinkage are observed (stenosis degree $=47 \%$, shrinkage degree $=$ 41\%). Arrow, Anastomosis; $A$, anal side; $O$, oral side.

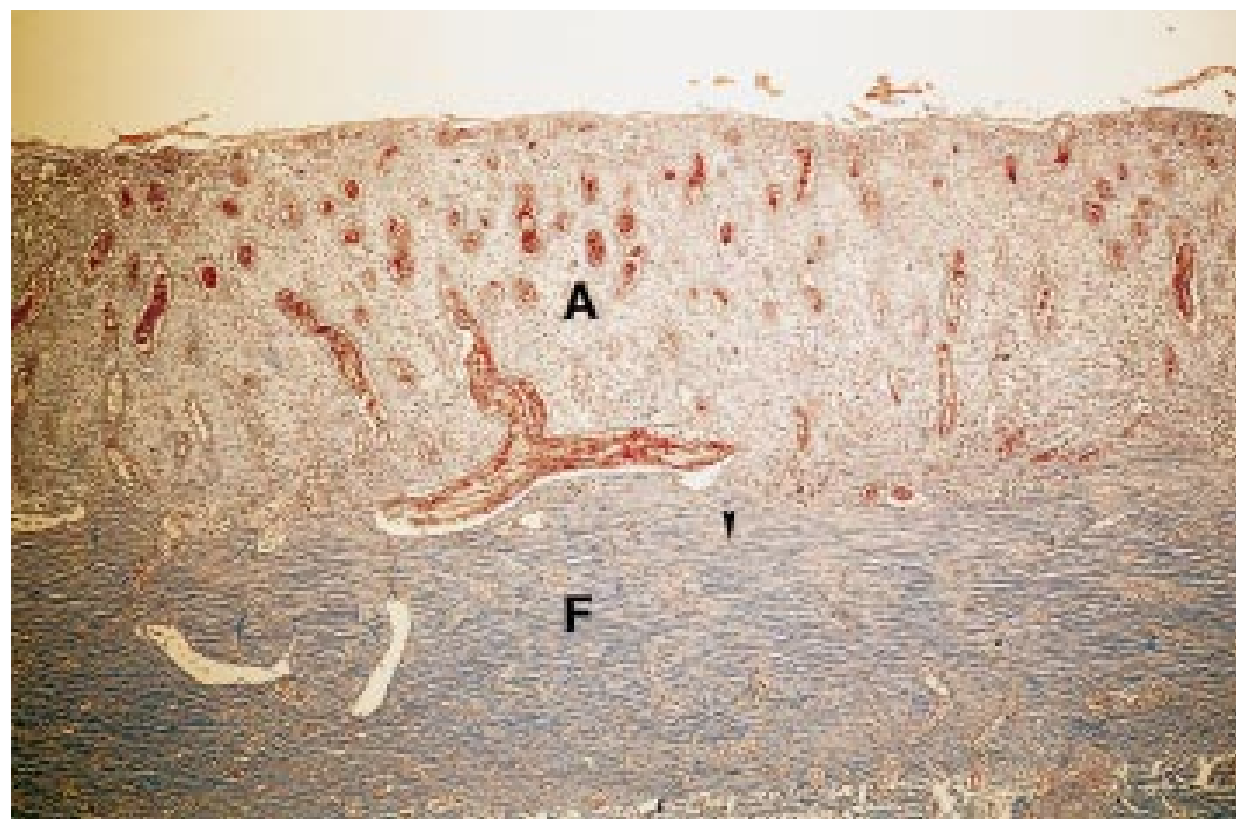

Fig 8. Microscopic findings in the middle of the regenerated esophagus at 1 month. The top is the luminal side. The inner amorphous collagen layer $(A)$ is composed of inflammatory cells with neovascularization, and the outer fibrous collagen layer $(F)$ consists of collagen fiber bundles aligned along the longitudinal axis of the esophagus (Masson's trichrome stain, original magnification $\times 80$, arrowhead: area of interest in Fig 9).

side) was observed in the middle of the regenerated esophagus, and prestenotic dilatation occurred on the oral side of the stenosis (Fig 3). The findings in the same dog at 24 months were similar to those at 3 months. The distance between the metal clips marking the anastomosis sites was the same (about $3.5 \mathrm{~cm}$ ) at 3 and 24 months on radiographic examination (Fig 4).

Typical endoscopic findings in dog 8 . Typical endoscopic findings were evident in $\operatorname{dog} 8$. At 1 month, the internal surface of the replaced esophagus was covered 


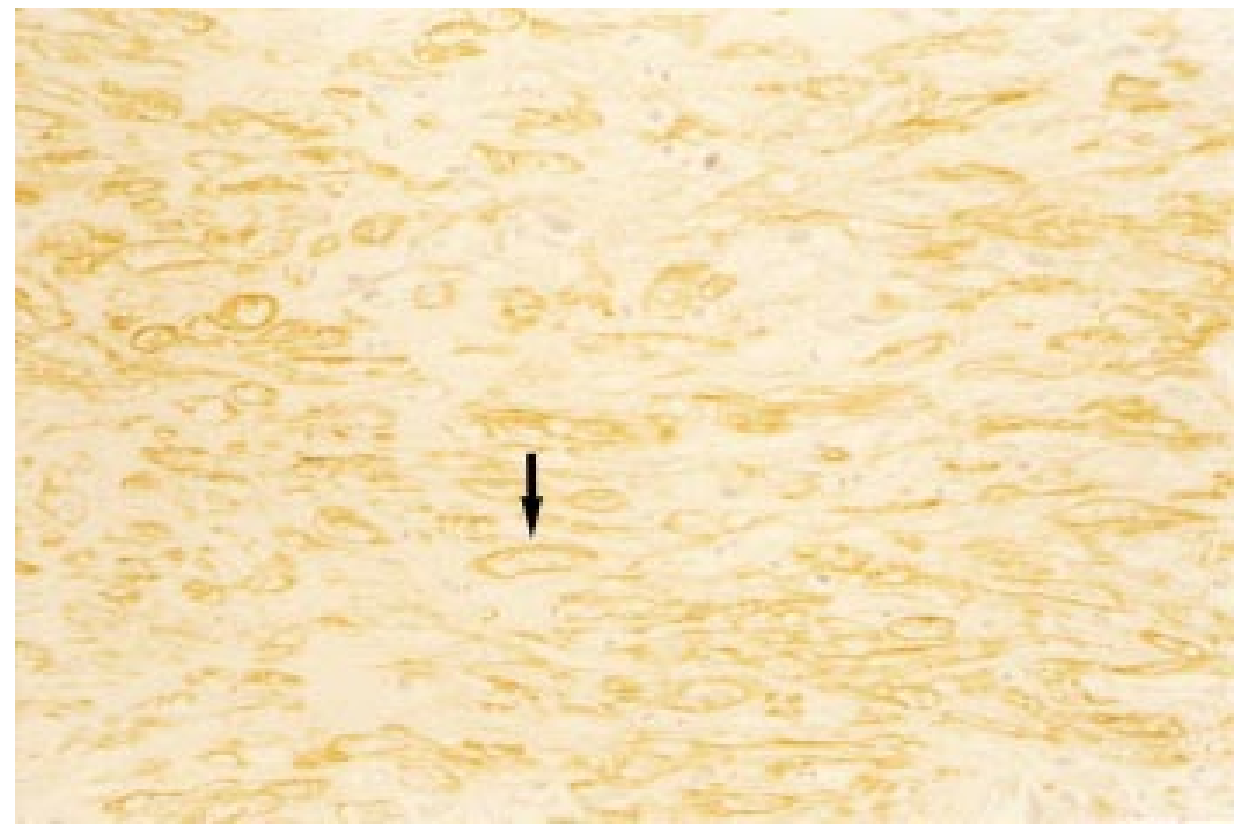

Fig 9. Immunofluorescence histologic study of the middle of the regenerated esophagus at 1 month after staining with anti-alpha-smooth muscle actin antibody (original magnification $\times 400$ ). A large number of cells positive for alpha-smooth muscle actin are observed (arrow). These are considered to be myofibroblasts.

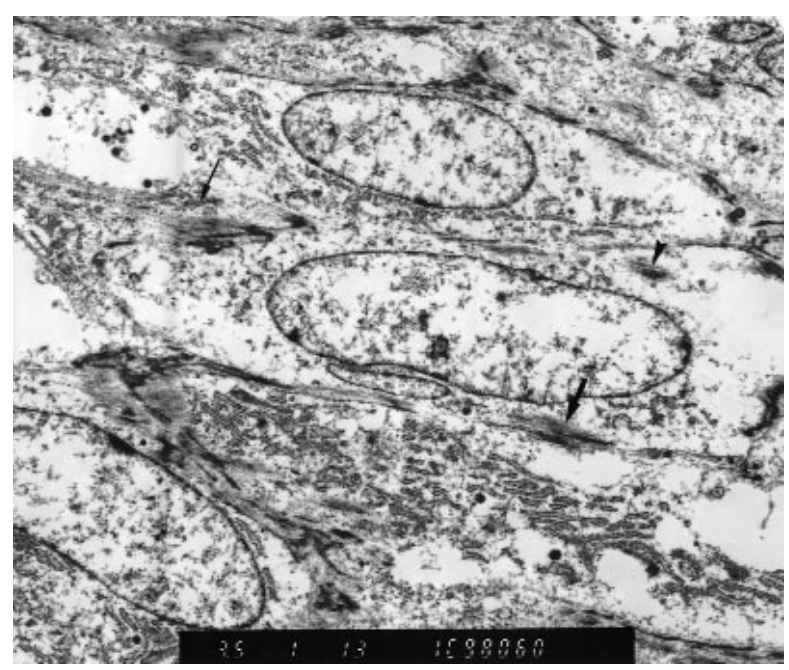

Fig 10. TEM appearance at 1 month of spindle cells that were positive for alpha-smooth muscle actin. The round nuclei are divided into 2 parts owing to the deep fold. The well-developed microfilaments (arrow) with dense bodies (arrowhead) are arranged parallel to the long axis of the cell. Rough endoplasmic reticulum (thin arrow) is also evident. The cells have characteristics intermediate between those of smooth muscle cells and fibroblasts. Therefore they are considered to be myofibroblasts.

completely with granulation tissue with an inflammatory appearance (Fig 5, left). At 3 months, the internal surface was completely covered with normal mucosa, and the sign of inflammation had disappeared. Stenosis was observed at the middle part (Fig 5, middle). Because the same findings were evident at $3,6,9,12$, and 24 months in $\operatorname{dog} 8$, the stenosis did not seem to advance after 3 months (Fig 5, right). Inasmuch as some cut sutures remained at the anastomotic sites, the anastomoses were easy to recognize with an endoscope. Neither stenosis nor granulation was evident at either anastomosis. In 5 other dogs, endoscopic examination was done for more than 3 months, and the findings were similar to those in $\operatorname{dog} 8$, although the degree of stenosis varied to a certain extent.

Macroscopic findings in the esophagus. Macroscopic examination was performed in 8 dogs. At 1 month in $\operatorname{dog} 1$, the internal surface of the regenerated esophagus was covered with severely inflammatory granulation tissue. No defect was observed in the regenerated esophagus, and the degree of stenosis was 13\% (Fig 6). At 3 months in dogs 3 and 4, the internal surface was covered with mucosa, and stenosis (degree of stenosis: $22 \%$ and $27 \%$, respectively) was still evident in the middle portion. In the dogs put to death at 6 ( $\operatorname{dog} 5), 12(\operatorname{dog} 7)$, and $24(\operatorname{dog} 8)$ months, stenosis in the middle part and shrinkage between the anastomoses were recognized (Table I). The internal surfaces were covered by mucosa with a normal appearance. The typical macroscopic appearance of the internal surface at 10 months $(\operatorname{dog} 6)$ is shown in Fig 7. The anastomosed 


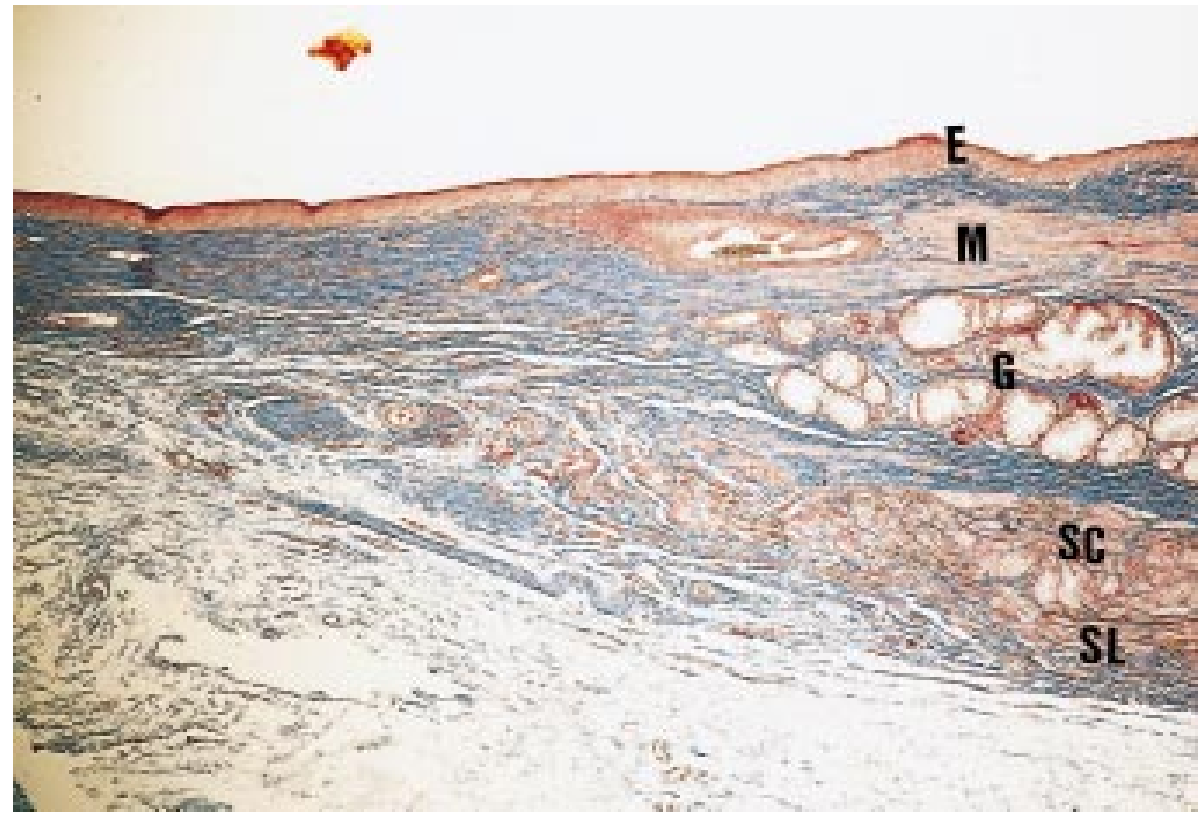

Fig 11. Microscopic findings near the anal anastomosis at 3 months. Top side is the luminal side. Stratified squamous epithelium covers the regenerated esophagus. The skeletal muscle layer has lost its inner circular and outer longitudinal original structure at the stumps (Masson's trichrome stain, original magnification $\times 50$ ). E, Mucosa; $M$, lamina muscularis mucosae; $G$, gland; $S C$, inner circular skeletal muscle layer; $S L$, outer longitudinal skeletal muscle layer.

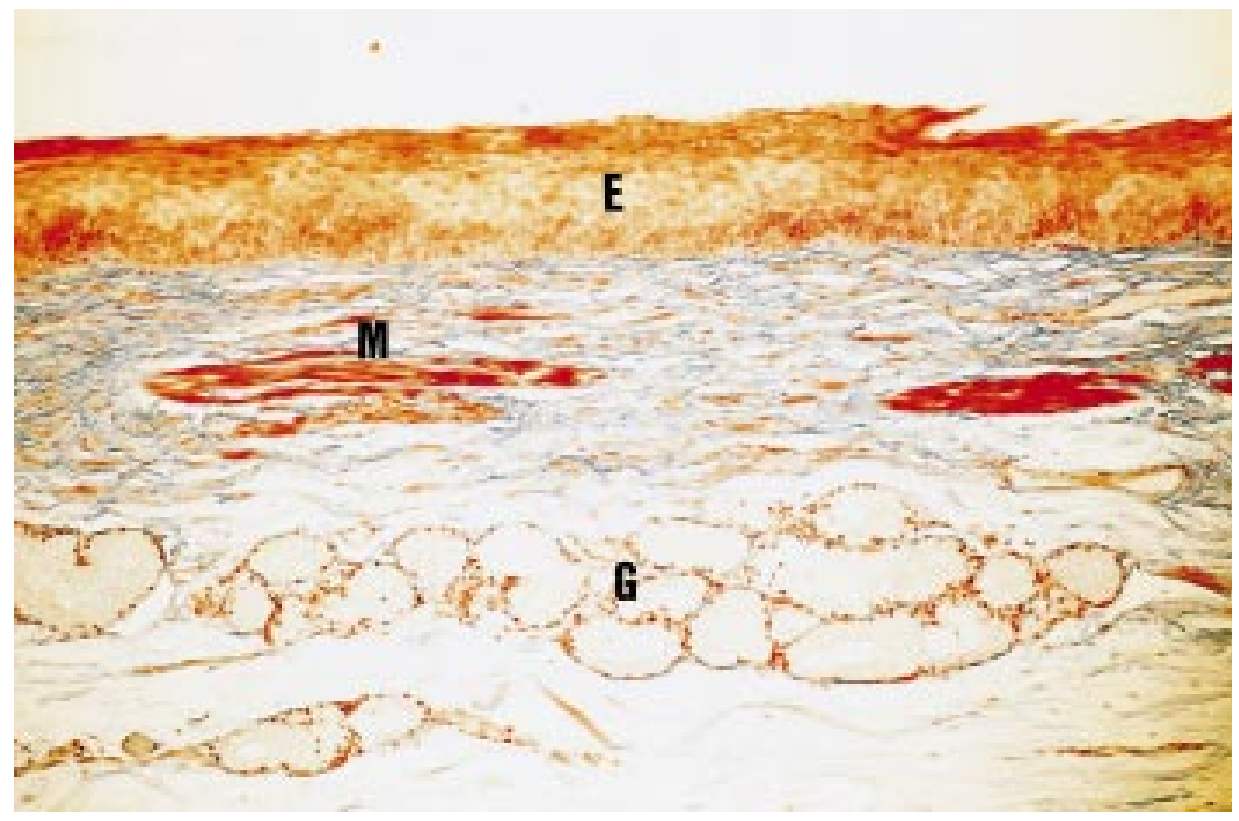

Fig 12. Microscopic appearance of the middle of the regenerated esophagus at 12 months. Ten layers or more of the stratified squamous epithelium have formed, beneath which islets of smooth muscle or esophageal glands have regenerated. The islets of smooth muscle are considered to be the interrupted lamina muscularis mucosae. The location of the mucosa, smooth muscle, and glands is similar to that in the normal esophagus (Masson's trichrome stain, original magnification $\times 200$ ). $E$, Mucosa; $M$, islets of smooth muscle; $G$, gland. 


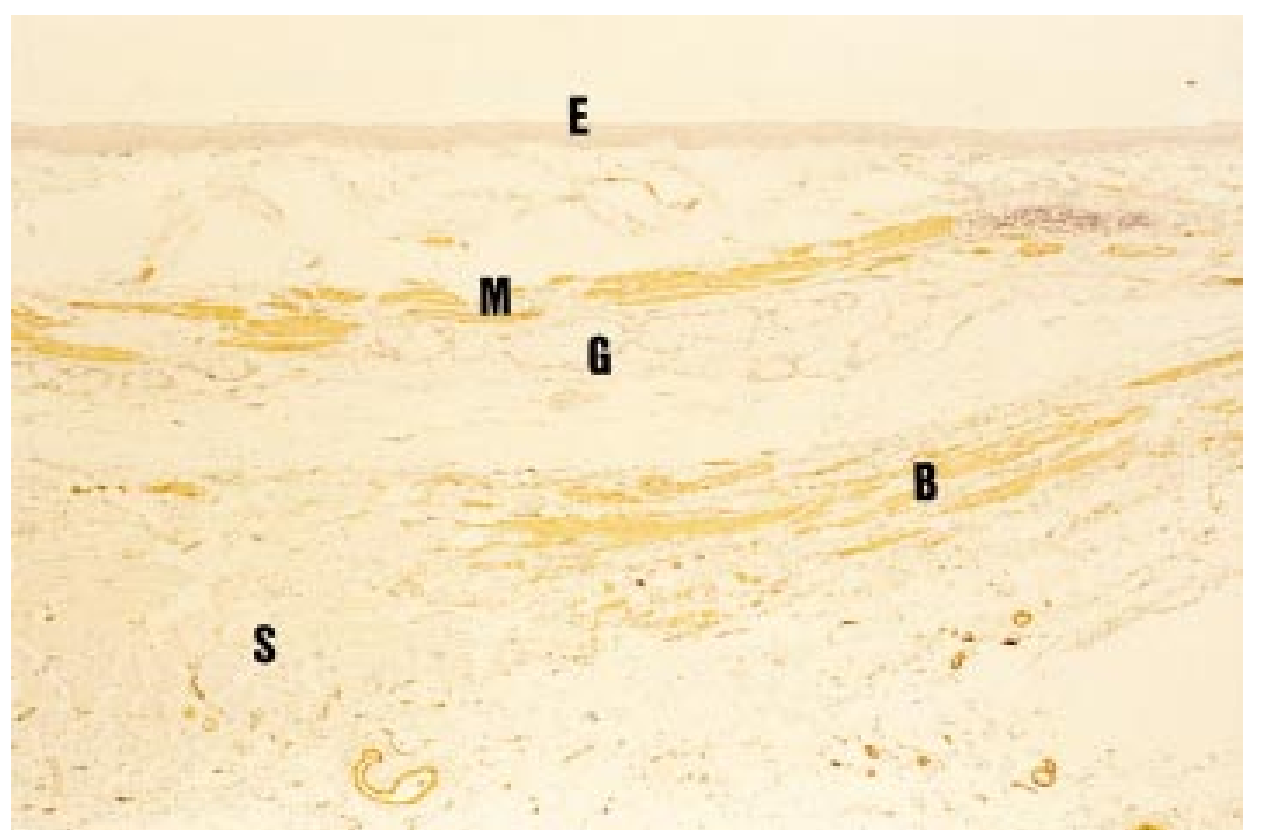

Fig 13. Immunohistologic findings near the regenerated esophagus at 12 months, stained with anti-alpha-smooth muscle actin antibody (original magnification $\times 100$ ). The smooth muscle has regenerated at the tip of the skeletal muscle layer. These smooth muscle bundles are connected with the lamina muscularis mucosae in the middle of the regenerated esophagus. $E$, Mucosa; $M$, lamina muscularis; $G$, gland; $S$, skeletal muscle; $B$, smooth muscle bundle.

portions were recognizable by the residual sutures. No anastomotic stenosis or granulation was observed in any of the specimens.

Histologic examination of the regenerated esophagus. Microscopic examination at 1 month showed that the epithelial layer was not present near the anastomoses and that the 5-cm gap had been replaced by a collagen layer $2 \mathrm{~mm}$ thick. This regenerated collagen layer was composed of 2 layers (Fig 8). The inner layer was about $0.5 \mathrm{~mm}$ thick and consisted of an amorphous collagen layer. The outer layer was $1.5 \mathrm{~mm}$ thick and constructed by fibrous collagen bundles about $6 \mu \mathrm{m}$ in diameter, which lay along the longitudinal axis of the esophagus, and spindle-shaped cells located among these bundles. The spindle cells all had a large, oval, clear nucleus and were positive for alpha-smooth muscle actin by immunofluorescence staining (Fig 9). TEM revealed that the cells positive for alpha-smooth muscle actin had nuclei with deep folds, well-developed microfilaments with dense bodies arranged parallel to the long axis of the cell, and rough endoplasmic reticulum. The cells did not have a laminin layer around the cytoplasm (Fig 10).

At 3 months, the internal surface of the regenerated esophagus was continuously covered with more than 5 layers of stratified squamous cells with a thickness of $30 \mu \mathrm{m}$. In the submucosal layer, thick but loose collagen bundles with a thickness of $0.4 \mathrm{~mm}$ were observed (Fig 11). However, the spindle cells, which were widely observed among the collagen bundles at 1 month and positive for alpha-smooth muscle actin, were hardly evident among the collagen bundles at 3 months. Smooth muscle, esophageal glands, and skeletal muscle were observed at the regeneration sites near the anastomoses. Islets of smooth muscle were observed in the submucosal layer in the middle of the regenerated esophagus. Immature myotubes were observed $2 \mathrm{~mm}$ from the oral margin of the host esophageal stump, but no myoblasts were detected in this area.

At 12 months, the internal surface of the regenerated esophagus was completely covered with more than 10 layers of stratified squamous cells with a thickness of $100 \mu \mathrm{m}$ (Fig 12). Throughout the whole length of the submucosal layer in the regenerated esophagus, collagen bundles, islets of smooth muscle cells, and esophageal glands were observed. The thickness of this layer was about $0.7 \mathrm{~mm}$. The structural conformation of these organs was sparse but normal in comparison with that of the normal esophagus. Mature myotubes were observed $2 \mathrm{~mm}$ from the skeletal muscle stumps, 
although skeletal muscle was not detected in the middle portion of the regenerated esophagus. At the end of the regeneration point of the skeletal muscle layer, smooth muscle cells had regenerated abundantly (Fig 13).

\section{Discussion}

The body weight of all dogs decreased until 3 months after the operation and thereafter recovered to the preoperative body weight up until 12 months. This suggested that the regenerated tissue could act sufficiently as an esophagus to transport orally ingested food into the stomach.

One of the causes of the body weight loss within 3 months was stenosis in the middle of the regenerated esophagus. This stenosis was hardly observed at 1 month just after removal of the silicone stent tube. Endoscopic or esophagographic examination of dog 8 confirmed that the stenosis advanced between 1 and 3 months but did not progress thereafter. This stenosis may have caused the observed vomiting and re-ingestion of vomitus and thus the chronic malnutrition evident in all the experimental dogs for up to 3 months. This refeeding behavior gradually disappeared after 3 months.

Macroscopic or microscopic findings and endoscopic examination revealed that a $5-\mathrm{cm}$ long gap in the thoracic esophagus had been replaced by cylindric granulation tissue at 1 month. The epithelium was located close to the anastomoses at 1 month but had covered the entire surface by 3 months. Because complete epithelialization was accomplished only after removal of the stent, the chronic inflammation caused by mechanical stimulation with the silicone tube might have delayed the regeneration of the epithelial layer. ${ }^{2-7}$ These findings agreed with previous studies, in which regeneration of the epithelium was observed after migration of the synthetic prosthesis. ${ }^{1-7}$

After recovery of the epithelial layer, the glands regenerated within 12 months throughout the regenerated esophagus. Gland regeneration was confirmed in the midportion, although this was not described in the previous reports of intrathoracic esophageal replacement. ${ }^{1-10}$

The cells positive for alpha-smooth muscle actin, which were observed among the collagen bundles at 1 month, might be considered myofibroblasts. ${ }^{22,23}$ This possibility was supported by the ultrastructural characteristics of these cells. ${ }^{24}$ The process of stenosis might result from wound contraction by such myofibroblasts. ${ }^{22-25}$ Because the myofibroblasts were hardly evident at 3 months, the progression of stenosis may have stopped by that time.
Moreover, the thick collagen bundles that made up the submucosal layer at the regeneration site at 1 month were thicker than those seen at 3 or 12 months. Formation of the epithelial layer and islets of the smooth muscle was complete within 3 months. The collagen bundle layer seemed to be synthesized by myofibroblasts and to act as a scaffold for tissue regeneration..$^{22-25}$

The cells positive for alpha-smooth muscle actin formed an interrupted line within 1 year, and their location was similar to that of the lamina muscularis mucosae of the normal esophagus. Therefore they could be considered as smooth muscle cells of the islets of the lamina muscularis mucosae.

The regeneration of skeletal muscle was observed only within $1 \mathrm{~mm}$ from the stumps of the native muscle layer. Immature myotubes were recognized at the ends of the myotubes within 3 months, and after 12 months the immature cells disappeared. ${ }^{26}$ Thus the regeneration of the skeletal muscle cells might have been been completed within 3 months after the operation in this experiment.

Even at 12 months, skeletal muscle was detected only near the anastomoses, and not in the middle of the regenerated esophagus. However, the stumps of the skeletal muscle layer were composed of not only few myotubes but also a large number of other types of cells. Because they showed staining for alpha-smooth muscle actin, these cells were considered to be smooth muscle cells. These cells regenerated beyond the anastomoses and fused with the lamina muscularis mucosae at their tips, suggesting that insufficient regeneration of the skeletal muscle was supplemented by regeneration of smooth muscle cells.

The main aim of this study was to replace a $5-\mathrm{cm}$ long gap in the intrathoracic esophagus in dogs. All the experimental dogs survived, and oral feeding became possible; one dog is still alive without problems after more than 26 months. However, contrary to our expectation, the regeneration of tissue, particularly in the skeletal muscle layer, was not complete. This might cause some delay in the regeneration of the esophagus in the thorax, compared with that in the cervix, and reflects the marked difference between these two locations. A couple of factors are responsible for this difference in regeneration. One is the poor blood supply in the thoracic esophagus, and the other is the difference in the surrounding tissue. In the thorax, the implanted prosthesis may be exposed to pleural effusion, which may wash away the collagen sponge. Preservation of the collagen as scaffolding for tissue regeneration may improve results in the thorax. 


\section{Conclusion}

A 5-cm long gap in the intrathoracic esophagus was replaced successfully by an artificial esophagus composed of a collagen sponge with a double-layered silicone tube. All 9 dogs survived for more than 1 month without problems, and $1 \mathrm{dog}$ is still alive after more than 26 months. Although central stenosis and shrinkage of the regenerated esophagus were observed, oral feeding was possible in all dogs. The mucosa, glands, and smooth muscle were regenerated at the replacement site. The skeletal muscle regenerated close to the anastomoses but not in the middle of the regenerated esophagus. Instead of skeletal muscle, smooth muscle regenerated at the stumps of the skeletal muscle layer.

\section{REFERENCES}

1. Leininger BJ, Peacock H, Neville WE. Esophageal mucosal regeneration following experimental prosthetic replacement of the esophagus. Surgery 1970;67:468-73.

2. Lister J, Altman P, Allison WA. Prosthetic substitution of thoracic esophagus in puppies: use of Marlex mesh with collagen or anterior rectus sheath. Ann Surg 1965;162:812-24.

3. Fukushima M, Kako N, Chiba K, Kawaguchi T, Kimura Y, Sato $\mathrm{M}$, et al. Seven-year follow-up study after the replacement of the esophagus with an artificial esophagus in the dog. Surgery 1983;93:70-7.

4. Goldsmith HS, Alday ES, Mikoshiba Y. Esophageal graft protection with intact omentum. Surg Gynecol Obstet 1973;137:231-4.

5. Rubenstein LH. Experiments with substitute esophagus. J Thorac Surg 1956;32:691-6.

6. Dumm JB, Macmanus JE, Anderson AA, McCormick RC. Esophageal reconstruction by means of prosthesis experimental and clinical experience. J Thorac Surg 1966;30:368-76.

7. Mark JBD, Briggs HC. Segmental replacement of the thoracic esophagus with woven Teflon. J Surg Res 1964;4:400-2.

8. Carachi R, Stokes KB, Brown TCK, Kent M. Esophageal anastomosis - an experimental model to study the anastomotic lumen and the influence of a transanastomotic tube. J Pediatr Surg 1984; 19:90-3.

9. Fryfogle JD, Cyrowski GA, Rothwell D, Rheault G, Clark T. Replacement of the middle third of the esophagus with a silicone rubber prosthesis: an experiment and clinical study. Dis Chest 1963;43:464-75.

10. Boyd TF. A prosthesis for replacement of the intrathoracic esophagus. Surg Forum 1962;13:256-8.

11. Yamamoto Y, Takimoto Y, Matsumoto K, Nakamura T, Shimizu
Y, Ueda H. Experimental replacement of the thoracic esophagus with a bioabsorbable artificial esophagus using collagen sponge-silicone double layer tube in canine. ASAIO J. In press.

12. Takimoto Y, Nakamura T, Yamamoto Y, Kiyotani T, Teramachi M, Shimizu Y. The experimental replacement of a cervical esophageal segment with an artificial prosthesis with the use of collagen matrix and a silicone stent. J Thorac Cardiovasc Surg 1998;116:98-106.

13. Takimoto Y, Okumura N, Nakamura T, Natsume T, Shimizu Y. Long-term follow-up of the experimental replacement of the esophagus with a collagen-silicone composite tube. ASAIO J 1993;39:M736-9.

14. Takimoto Y, Teramachi M, Okumura N, Nakamura T, Shimizu Y. Relationship between stenting time and regeneration of neoesophageal submucosal tissue. ASAIO J 1994;40:M793-7.

15. Natsume T, Ike O, Okada T, Takimoto N, Shimizu Y, Ikada Y. Porous collagen sponge for esophageal replacement. J Biomed Mater Res 1993;27:867-75.

16. Ike O, Shimizu Y, Okada T, Natsume T, Watanabe S, Ikada Y, et al. Experimental studies on an artificial esophagus for the purpose of neoesophageal epithelialization using a collagen-coated silicone tube. ASAIO Trans 1989;35:226-8.

17. Stenzel KH, Dunn MW, Rubin AL, Miyata T. Collagen gels: design for a vitreous replacement. Science 1969;164:1282-3.

18. Chvapil M. Collagen sponge: theory and practice of medical applications. J Biomed Mater Res 1977;11:721-41.

19. Ma XH, Noishiki Y, Yamane Y, Iwai Y, Marato D, Matsumoto A. Thermal cross-linkage for biologically degradable materials: preliminary report. ASAIO J 1996;42:M866-71.

20. Weadock KS, Miller EJ, Bellincampi LD, Zawadsky JP, Dunn MG. Physical crosslinkaging of collagen fibers: comparison of ultraviolet irradiation and dehydrothermal treatment. J Biomed Mater Res 1995;29:1373-9.

21. Weadock KS, Millar EJ, Keuffel EL, Dunn MG. Effect of physical crosslinking methods on collagen-fiber durability in proteolytic solutions. J Biomed Mater Res 1996;32:221-6.

22. Gabbiani G. The biology of the myofibroblast. Kidney Int 1992;41:530-2.

23. Desmouliere A. Factor influencing myofibroblast differentiation during wound healing and fibrosis. Cell Biol Int 1995;19:471-6.

24. Skalli O, Gabbiani G. The biology of the myofibroblast relationship to wound contraction and fibrocontractive diseases. In: Clark RAF, Henson PM, editors. The molecular and cellular biology of wound repair. New York: Plenum Press; 1988. p. 373402.

25. Ariyan S, Enriquez R, Krizek TJ. Wound contraction and fibrocontractive disorders. Arch Surg 1978;113:1034-46.

26. Hurme T, Kalimo H. Activation of myogenic precursor cells after muscle injury. Med Sci Sports Exerc 1992;24:197-205. 